\title{
Point of care ultrasound screening for deep vein thrombosis in critically ill COVID-19 patients, an observational study
}

Sarah Galien ${ }^{1}$, Michael Hultström ${ }^{1,2}$, Miklós Lipcsey ${ }^{1,3}$, Karl Stattin $^{1}$, Robert Frithiof ${ }^{1}$, Jacob Rosén ${ }^{1 *}$ (D) and the Uppsala Intensive Care COVID-19 Research Group

\begin{abstract}
Background: Deep vein thrombosis (DVT) is common in critically ill patients with Coronavirus disease 2019 (COVID19) and may cause fatal pulmonary embolism (PE) prior to diagnosis due to subtle clinical symptoms. The aim of this study was to explore the feasibility of bedside screening for DVT in critically ill COVID-19 patients performed by physicians with limited experience of venous ultrasound. We further aimed to compare inflammation, coagulation and organ dysfunction in patients with and without venous thromboembolism (VTE).

Methods: This observational study included patients with COVID-19 admitted to the intensive care unit (ICU) of a tertiary hospital in Sweden and screened for DVT with proximal compression ultrasound of the lower extremities between April and July 2020. Screening was performed by ICU residents having received a short online education and one hands-on-session. Pathological screening ultrasound was confirmed by formal ultrasound whereas patients with negative screening underwent formal ultrasound on clinical suspicion. Clinical data, laboratory findings and follow-up were extracted from medical records.

Results: Of 90 eligible patients, 56 were screened by seven ICU residents with no $(n=5)$ or limited $(n=2)$ previous experience of DVT ultrasound who performed a median of 4 (IQR 2-19) examinations. Four (7.1\%) patients had pathological screening ultrasound of which three (5.6\%) were confirmed by formal ultrasound. None of the 52 patients with negative screening ultrasound were diagnosed with DVT during follow-up. Six patients were diagnosed with PE of which four prior to negative screening and two following negative and positive screening respectively. Patients with VTE $(n=8)$ had higher median peak D-dimer (24.0 (IQR 14.2-50.5) vs. 2.8 (IQR 1.7-7.2) $\mathrm{mg} / \mathrm{L}, p=0.004$ ), mean peak C-reactive protein (363 (SD 80) vs. 285 (SD 108) $\mathrm{mg} / \mathrm{L}, p=0.033$ ) and median peak plasma creatinine (288 (IQR 131-328) vs. 94 (IQR 78-131) $\mu \mathrm{mol} / \mathrm{L}, p=0.009)$ compared to patients without VTE $(n=$ 48). Five patients (63\%) with VTE received continuous renal replacement therapy compared to six patients (13\%) without VTE $(p=0.005)$.

\footnotetext{
* Correspondence: Jacob.rosen@surgsci.uu.se

'Department of Surgical Sciences, Anaesthesiology and Intensive Care

Medicine, Uppsala University, entrance 78, 1 floor, 75185 Uppsala, Sweden

Full list of author information is available at the end of the article
}

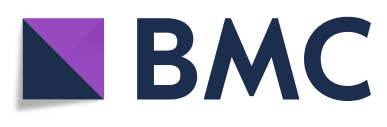

(c) The Author(s). 2021 Open Access This article is licensed under a Creative Commons Attribution 4.0 International License, which permits use, sharing, adaptation, distribution and reproduction in any medium or format, as long as you give appropriate credit to the original author(s) and the source, provide a link to the Creative Commons licence, and indicate if changes were made. The images or other third party material in this article are included in the article's Creative Commons. licence, unless indicated otherwise in a credit line to the material. If material is not included in the article's Creative Commons licence and your intended use is not permitted by statutory regulation or exceeds the permitted use, you will need to obtain permission directly from the copyright holder. To view a copy of this licence, visit http://creativecommons.org/licenses/by/4.0/ The Creative Commons Public Domain Dedication waiver (http://creativecommons.org/publicdomain/zero/1.0/) applies to the data made available in this article, unless otherwise stated in a credit line to the data. 
(Continued from previous page)

Conclusion: ICU residents with no or limited experience could detect DVT with ultrasound in critically ill COVID-19 patients following a short education. VTE was associated with kidney dysfunction and features of hyperinflammation and hypercoagulation.

Trial registration: ClinicalTrials ID: NCT04316884. Registered 20 March 2020.

Keywords: COVID-19, ICU, Deep vein thrombosis, Screening, Point of care ultrasound

\section{Introduction}

Hypercoagulation and associated deep vein thrombosis (DVT) is a common and severe consequence of the inflammatory response in critically ill patients with Coronavirus disease 2019 (COVID-19) and has led to implementation of COVID-19 specific thromboprophylaxis regimens [1-7]. Symptoms of DVT in the critically ill are often vague but may cause life-threatening pulmonary embolism (PE) and most patients will be considered high risk for DVT using conventional risk assessment scores, limiting their utility [8]. Routine screening for DVT could therefore be beneficial for early diagnosis of asymptomatic DVT in patients with COVID-19 admitted to intensive care units (ICU) [9].

Complete duplex ultrasound (CDUS) of the entire lower extremity is the recommended imaging technique for evaluation of suspected DVT [10]. CDUS is timeconsuming and requires considerable training to perform and interpret and is therefore only performed by designated operators. During the COVID-19 pandemic, screening with CDUS would be limited by availability, expose ultrasound operators to infection and may increase inhospital contamination [11]. As an alternative to CDUS, two-region compression ultrasound (2-CUS) of the common femoral and popliteal veins only, is accurate for diagnosing DVT in non-COVID-19 patients and can be performed by emergency and critical care physicians [1214]. Further, 2-CUS point-of-care screening has good agreement with formal ultrasound in critically ill COVID19 patients [15]. An extended compression ultrasound (ECUS) improves sensitivity by diagnosing thrombi isolated to the superficial femoral vein [16].

DVT screening in COVID-19 patients has been described using ultrasound of the entire lower extremity [17-24], 2-CUS [25] and ECUS [26, 27]. However, in previous studies screening was performed by physicians experienced in DVT studies.

We therefore aimed to investigate the feasibility of bedside screening for DVT in critically ill COVID-19 patients performed by physicians unexperienced in venous ultrasound by investigating the results of a residentled DVT screening programme implemented at our ICU in April 2020. The secondary aim was to compare organ dysfunction, inflammation and coagulation between critically ill COVID-19 patients with and without venous thromboembolism (VTE).

\section{Material and methods}

Study design and patient population

This was an observational study of patients admitted to a mixed medical and surgical ICU who were screened for DVT in a clinically implemented programme between 10th April and 14th July 2020 at Uppsala University Hospital, a tertiary care centre in Sweden. The study was performed as a sub-analysis of patients included in a cohort study (PronMed) [28] approved by the National Ethical Review Agency (EPM; 2020-01623). Written informed consent was obtained from patients, or next of kin if the patient was unable to give consent. The study was registered a priori 20 March 2020 (ClinicalTrials ID: NCT04316884).

All patients admitted to the ICU with COVID-19 diagnosis confirmed by positive SARS-CoV-2 reverse transcription polymerase chain reaction tests on nasoor oropharyngeal swabs were eligible for lower extremity DVT screening with proximal compression ultrasound (2-CUS or ECUS) as soon as possible after ICU admission and included in the present analysis if they were $\geq 18$ years old and had respiratory failure $\left(\mathrm{PaO}_{2} /\right.$ $\mathrm{FiO}_{2}$ ratio $\left.\leq 40 \mathrm{kPa}(300 \mathrm{mmHg})\right)$ [29].

\section{Study setting}

ICU residents were recruited to a DVT screening programme and received a 25 -min online video tutorial followed by a single hands-on session supervised by a physician (JR) certified in echocardiography but with limited experience in DVT studies (20 examinations). 2CUS and ECUS were taught according to consensus guidelines [10] and performed using high frequency linear array probes on GE Logiq S8 (GE Healthcare, Chicago, IL, USA) or Philips Sparq (Philips Ultrasound. Inc., Bothell, WA, USA) ultrasound machines. The ultrasound examination was considered pathological if compression did not cause complete collapse of the examined vein (Fig. 1). Patients with pathological screening were referred for formal CDUS and patients with negative screening were followed up and referred for formal ultrasound on clinical suspicion. 

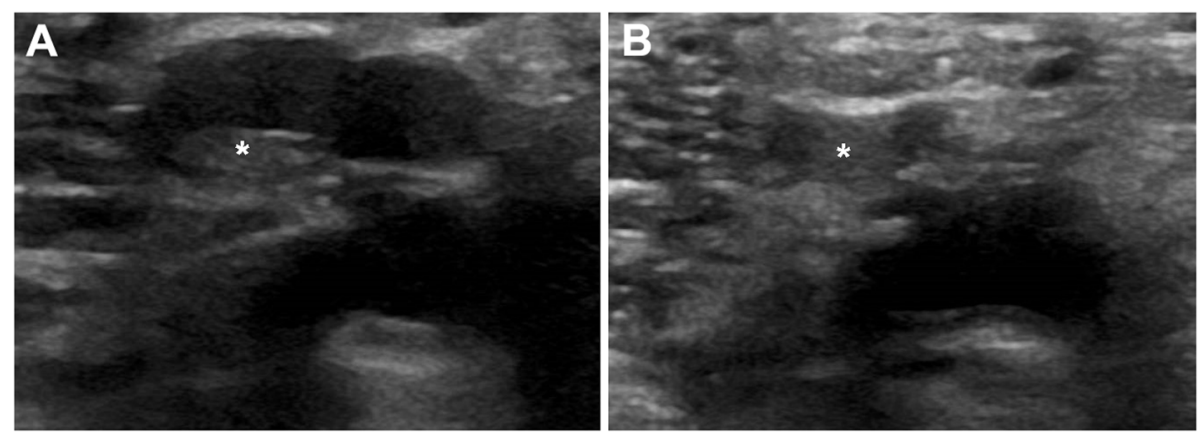

Fig. 1 Screening ultrasound. The images display the bifurcation of the popliteal vein into the calf veins. The thrombus, marked with an asterisk $\left({ }^{*}\right)$, can be distinguished even without compression in the left vein (a). The left vein cannot be fully compressed, which is diagnostic of thrombosis, whereas the right vein demonstrates normal compression with full collapsibility (b). This pathological screening ultrasound was later confirmed by formal ultrasound

Critically ill COVID-19 patients in our ICU received weight-based low molecular weight heparin (LMWH) thromboprophylaxis with dalteparin sodium (Fragmin, Pfizer, New York, NY, USA). Patients $<50 \mathrm{~kg}$ received 5000 international units (IU) daily, patients $50-90 \mathrm{~kg}$ received 10,000 IU daily and patients $>90 \mathrm{~kg}$ received 150 $\mathrm{IU} / \mathrm{kg}$ daily. Alterations in LMWH dosage was made according to anti-factor Xa-activity assays every three to seven days (COVID-19 modified target ranges per local guidelines: $0.50-0.80 \mathrm{kIE} / \mathrm{L}$ for prophylaxis (normally $0.20-0.45 \mathrm{kIE} / \mathrm{L}$ ) and $0.90-1.20 \mathrm{kIE} / \mathrm{L}$ for treatment of confirmed VTE (normally 0.60-0.90 kIE/L)). Anti-factor Xa-assays were sampled three hours after LMWH dosing and were run using STA ${ }^{\circ}$-Liquid Anti-Xa (Stago, Asnières-sur-Seine Cedex, France) [30]. D-dimer values were not used to modify LMWH dosage. The D-dimer reagent used was $\mathrm{STA}^{\circ}$-Liatest ${ }^{\circ} \mathrm{D}-\mathrm{Di}$ Plus (Stago, Asnières-sur-Seine Cedex, France) [31].

\section{Data collection}

Information regarding demographic data, medical history, comorbidities, anticoagulation, DVT screening, subsequent DVT diagnosis, computed tomography angiography (CTPA) results and mortality was collected from electronic medical records until 90 days after inclusion, transfer to another hospital or time of death. Laboratory data were extracted from medical records during ICU stay.

\section{Statistical methods}

Statistical analyses were performed in Microsoft Excel (Redmond, WA, USA) and R, version 3.6.3 (R Commander, R Foundation for Statistical Computing, Vienna, Austria, https://www.R-project.org/). Continuous variables were expressed as means and standard deviations (SD) or medians and interquartile ranges (IQR) as appropriate. Categorical variables were expressed as numbers and percentages. Normally and non-normally distributed continuous data was compared using independent $\mathrm{t}$-test and Mann-Whitney U-test respectively and Fisher's exact tests were used to compare categorical data. Two-sided $p$-values $<0.05$ were considered statistically significant.

\section{Results}

\section{Patient characteristics}

Of 90 eligible patients, 56 were screened for DVT between the 27th of April and the 14th of July 2020. Mean age was 62.3 (SD 13.5) years, median body mass index was 29.0 (IQR $26.7-34.0) \mathrm{kg} / \mathrm{m}^{2}$ and 13 (23\%) patients were female (Table 1). The most common comorbidities were hypertension, pulmonary disease and diabetes mellitus. Two patients (3.6\%) had a medical history of combined DVT and PE prior to COVID-19.The median duration of symptoms before ICU admission was 10 days (IQR 8-12) and the median Simplified Acute Physiology Score (SAPS 3) [32] on admission was 53 (SD 10). Fortysix patients $(82 \%)$ received thromboprophylaxis with subcutaneous injections of dalteparin and five patients (8.9\%) received therapeutic anticoagulation with dalteparin or unfractionated heparin prior to screening. Five patients $(8.9 \%)$ did not receive anticoagulation prior to screening, either due to contraindication or because they were screened prior to administration of the first dose of LMWH.

\section{Ultrasound screening}

Seven ICU residents volunteered to participate in the screening programme. Two physicians had limited experience (10-20 prior examinations) of DVT ultrasound, whereas the other physicians had none. They performed a median of 4 (IQR 2-19) screening ultrasounds. Patients were screened with either 2-CUS (61\%) or ECUS (39\%) at median day 3 (IQR 1-5) after ICU admission. 
Table 1 Patient characteristics for all patients and for patients diagnosed with VTE and those with no VTE during the ICU stay

\begin{tabular}{|c|c|c|c|}
\hline Variable & Total $(n=56)$ & No VTE $(n=48)$ & $\begin{array}{l}\mathrm{VTE} \\
(\mathrm{DVT} \pm \mathrm{PE} ; n=3, \mathrm{PE} n=5)\end{array}$ \\
\hline Age, years (SD) & $62.3(13.5)$ & $61.6(14.4)$ & $65.5(3.6)$ \\
\hline Female sex n(\%) & $13(23)$ & $13(27)$ & $0(0)$ \\
\hline $\mathrm{BMI}, \mathrm{kg} / \mathrm{m}^{2}$ (IQR) & $29.0(26.7-34.0)$ & $29.2(26.6-34.1)$ & $28.5(27.2-31.6)$ \\
\hline Hypertension n(\%) & $29(52)$ & $23(48)$ & $6(75)$ \\
\hline \multicolumn{4}{|l|}{ Pulmonary disease } \\
\hline Asthma $\mathrm{n}(\%)$ & $10(18)$ & $9(19)$ & $1(13)$ \\
\hline COPD n(\%) & $5(8.9)$ & $5(10)$ & $0(0)$ \\
\hline Unspecified n(\%) & $1(1.8)$ & $1(2.1)$ & $0(0)$ \\
\hline Ischemic heart disease $n(\%)$ & $7(13)$ & $6(13)$ & $1(13)$ \\
\hline History of VTE n(\%) & $2(3.6)$ & $1(2.1)$ & $1(13)$ \\
\hline Diabetes mellitus n(\%) & $12(21)$ & $10(21)$ & $2(25)$ \\
\hline Ongoing smoking n(\%) & $4(7.3)$ & $4(8.5)$ & $0(0)$ \\
\hline Previous smoking n(\%) & $12(22)$ & $10(21)$ & $2(25)$ \\
\hline Heart failure n(\%) & $2(3.6)$ & $2(4.2)$ & $0(0)$ \\
\hline Days from symptom onset at ICU admission, (IQR) & $10(8-12)$ & $9(8-11)$ & $10(9-13)$ \\
\hline SAPS 3 score at ICU admission (SD) & $53(10)$ & $53(10)$ & $52(8)$ \\
\hline \multicolumn{4}{|l|}{ Parenteral anticoagulation prior to DVT screening } \\
\hline Prophylactic dose $n(\%)$ & $46(82)$ & $43(90)$ & $3(38)$ \\
\hline Therapeutic dose $\mathrm{n}(\%)$ & $5(8.9)$ & $0(0)$ & $5(63)$ \\
\hline
\end{tabular}

Data are presented as mean (standard deviation), median (interquartile range) and absolute numbers (percentages). VTE Venous thromboembolism, BMI Body mass index, COPD Chronic obstructive pulmonary disease, PE Pulmonary embolism, DVT Deep vein thrombosis, ICU Intensive care unit, SAPS 3: Simplified Acute Physiology Score 3 [32]

Four patients (7.1\%) had a pathological screening result, out of which three $(5.4 \%)$ were corroborated by formal CDUS. Two residents with no previous DVT ultrasound experience had one true positive screening examination each. One resident with limited prior experience had one true positive and one false positive examination. All confirmed DVT were localized in the popliteal veins and all but one was unilateral. None of the 52 patients with initial negative screening ultrasound were diagnosed with DVT during follow-up.

\section{Venous thromboembolism, inflammation and organ dysfunction}

Thirty patients (54\%) underwent at least one CTPA, of which thirteen (23\%) had CTPA performed after ultrasound screening. Six patients were diagnosed with $\mathrm{PE}$; four after negative screening, and two after negative and positive screening respectively.

Patients with VTE (DVT $\pm \mathrm{PE} ; n=3$, PE $n=5)$ were older, had higher peak plasma values of $\mathrm{C}$-reactive protein (CRP), D-dimer and creatinine but no statistically significant difference in peak plasma values of troponin I and N-terminal pro brain natriuretic peptide (NT-proBNP) compared to patients without VTE $(n=48)$ (Table 2).
More patients with VTE received continuous renal replacement therapy (CRRT) during their ICU stay than patients without VTE $(p=0.005)$ but there was otherwise no difference in ICU length-of-stay or the proportion of patients receiving mechanical ventilation or vasoactive treatment.

Eleven patients (20\%) died during the ICU stay, and an additional three patients (5.5\%) died within 90 days from inclusion. There were no differences in mortality for patients diagnosed with VTE compared to patients without VTE at ICU discharge or at three-month follow-up (Table 3). Seven patients (16\%) were transferred to other hospitals, resulting in loss to follow-up for subsequent VTE diagnosis for all patients and vital status for one patient.

\section{Discussion}

The main finding of this study was that ICU residents provided with a short education could find DVT in critically ill COVID-19 patients. This is, to our knowledge, the first study of DVT screening by physicians with no or limited previous experience in DVT ultrasound in this setting. Three of four positive findings were corroborated by formal ultrasound and no DVT were diagnosed in patients with negative screening ultrasound during follow-up, suggesting acceptable sensitivity, specificity 
Table 2 Peak plasma values from laboratory data during ICU stay and comparison between patients with and without VTE

\begin{tabular}{|c|c|c|c|c|}
\hline Laboratory data & Total $(n=56)$ & No VTE $(n=48)$ & $\begin{array}{l}\text { VTE } \\
(\mathrm{DVT} \pm \mathrm{PE} ; n=3, \mathrm{PE} n=5)\end{array}$ & $p$-value \\
\hline D-dimer, mg/L (IQR) & $3.3(1.7-8.1)$ & $2.8(1.7-7.2)$ & $24.0(14.2-50.5)$ & 0.004 \\
\hline CRP, mg/L (SD) & $296(108)$ & $285(108)$ & $363(80)$ & 0.033 \\
\hline Ferritin, $\mu \mathrm{g} / \mathrm{L}(\mathrm{IQR})$ & $2879(1643-4617)$ & $2781(1643-4421)$ & $3916(2369-7537)$ & 0.262 \\
\hline IL-6, ng/L (IQR) & $207(100-334)$ & $193(91-274)$ & $302(197-639)$ & 0.096 \\
\hline Creatinine, $\mu \mathrm{mol} / \mathrm{L}(\mathrm{IQR})$ & $95(78-146)$ & $94(78-131)$ & $288(131-328)$ & 0.009 \\
\hline Troponin I, ng/L (IQR) & 21 [10-93] & $21(10-76)$ & $79(20-172)$ & 0.167 \\
\hline NT-pro-BNP, ng/L (IQR) & $1135(424-3603)$ & 937 (406-3203) & $3700(1003-5630)$ & 0.167 \\
\hline
\end{tabular}

Data are presented as mean (standard deviation) or median (interquartile range). VTE: Venous thromboembolism, DVT: Deep vein thrombosis, CRP: C-reactive protein, IL6: Interleukin 6, NT-pro-BNP: N-Terminal pro brain natriuretic peptide. Laboratory reference ranges: $C R P<5 \mathrm{mg} / \mathrm{L}$; $D$-dimer $<0,50 \mathrm{mg} / \mathrm{L}$ (non-age-adjusted); Ferritin male patients $25-310 \mu \mathrm{g} / \mathrm{L}$, female patients $10-155 \mu \mathrm{g} / \mathrm{L}$ (non-age-adjusted); lL-6 < 7,0 ng/L; plasma creatinine male patients $60-105 \mu \mathrm{mol} / \mathrm{L}$, female patients $45-90 \mu \mathrm{mol} / \mathrm{L}$; NT-pro-BNP male patients < $230 \mathrm{ng} / \mathrm{L}$, female patients $<330 \mathrm{ng} / \mathrm{L}$ (non-age-adjusted); Troponin I male patients $<35 \mathrm{ng} / \mathrm{L}$, female patients $<16 \mathrm{ng} / \mathrm{L}$

and predictive values, whereas the small study sample and few events prohibits the calculation of precise estimates.

Two meta-analyses in non-COVID-19 settings have found that emergency physician-performed ultrasound had a high agreement with formal ultrasound and a sensitivity of $95-96 \%$ and specificity of $96-97 \%[12,13]$. An intensivist-performed ultrasound screening study for proximal DVT in trauma patients reported a positive predictive value of $92 \%$, a negative predictive value of $97 \%$ and a specificity of $99 \%$ compared to formal ultrasound, corroborating our results [33]. However, the sensitivity was only $69 \%$ due to the occurrence of nonocclusive DVT, which are more difficult to detect because the veins will partially collapse with compression. Patients with negative screening were not referred for CDUS in our study, and small non-occlusive thromboses could thus have been missed.

We found DVT in 5.4\% of screened patients. Previous screening studies in critically ill COVID-19 patients have found proximal lower extremity DVT in $10-23 \%$ of included patients $[15,20,22,26]$. However, standard prophylactic dose of LMWH was used in these studies and repeated scanning in three studies led to additional DVT diagnoses $[15,20,22]$, whereas in the present study, a higher-dose thromboprophylaxis regimen was used and screening was only performed once, which may at least in part explain our relatively low rate of diagnosed DVT.

Five patients were diagnosed with PE prior to or following negative screening ultrasound. This may have several explanations, including false negative screening, subsequent proximal leg thrombosis or emboli from other venous territories. Extensive ultrasound screening of all extremities and the central venous system will diagnose additional DVT compared to proximal lower extremity screening alone [24], although feasibility is limited in absence of experienced sonographers, and patients with PE may still be DVT negative [34] due to insitu pulmonary immunothrombosis [35].

We found a higher peak D-dimer value in COVID-19 patients with VTE compared to patients who did not have VTE, in line with previous reports [4, 5, 22, 24]. Elevated D-dimer correlates with poor prognosis, and among patients with $\mathrm{D}$-dimer $>3 \mathrm{mg} / \mathrm{L}$ the use of thromboprophylaxis is associated with lower mortality [2]. Patients diagnosed with VTE had higher peak CRP values compared to those who were not, consistent with a recent study [36]. We found no difference in interleukin-6 (IL-6) values between VTE and non-VTE patients, but

Table 3 Patient outcomes and comparison between patients with and without VTE

\begin{tabular}{|c|c|c|c|c|}
\hline Outcomes & Total $(n=56)$ & $\begin{array}{l}\text { No VTE } \\
(n=48)\end{array}$ & $\begin{array}{l}\mathrm{VTE} \\
(\mathrm{DVT} \pm \mathrm{PE} ; n=3, \mathrm{PE} n=5 \text { ) }\end{array}$ & $p$-value \\
\hline ICU length-of-stay, days (IQR) & $12(6-20)$ & $10(6-18)$ & $17(15-25)$ & 0.087 \\
\hline Died during ICU stay n(\%) & $11(20)$ & $9(19)$ & $2(25)$ & 0.649 \\
\hline Died within 90 days n(\%) & $14(25)$ & $12(26)$ & $2(25)$ & $>0.999$ \\
\hline Lowest $\mathrm{PaO}_{2} / \mathrm{FiO}_{2}$-ratio, $\mathrm{kPa}$ (IQR) & $9.8(8.6-11.0)$ & $9.8(8.2-11.0)$ & $9.8(9.4-11.1)$ & 0.510 \\
\hline Vasoactive treatment $\mathrm{n}(\%)$ & $41(73)$ & $34(71)$ & $7(88)$ & 0.428 \\
\hline CRRT n(\%) & $11(20)$ & $6(13)$ & $5(63)$ & 0.005 \\
\hline Mechanical ventilation $\mathrm{n}(\%)$ & $35(63)$ & $28(58)$ & $7(88)$ & 0.236 \\
\hline
\end{tabular}

Data are presented as median (interquartile range) or absolute numbers (percentages). VTE Venous thromboembolism, PE Pulmonary embolism, DVT Deep vein thrombosis, ICU Intensive care unit, CRRT Continuous renal replacement therapy 
the analysis may be hampered by low statistical power. However, LMWH lowers IL-6 levels [37] and the high LMWH doses used in this cohort could possibly influence these results.

Although patients with PE may present with right ventricular strain and elevated levels of cardiac biomarkers [38], we found no difference in peak values of troponin-I and NT-pro-BNP in patients with and without VTE in our study. COVID-19 is associated with other causes of myocardial injury than PE, including ischemia, hypoxemia, pulmonary hypertension and myocarditis, which are likely to attenuate differences in troponin-I and NTpro-BNP values between VTE and non-VTE patients [39]. Also, patients with COVID-19 and PE are reported to have less clot burden and associated right ventricular strain compared to other patients with PE [35], which further may contribute to these findings.

Renal dysfunction and CRRT was more common in patients with VTE compared to patients without VTE. Both VTE $[5,23]$ and acute kidney injury (AKI) [40] are more common in severely ill COVID-19 patients compared to patients with mild disease. AKI is further associated with higher levels of biomarkers of inflammation and coagulation and in-hospital death in COVID-19 patients [41, 42]. AKI and VTE may thus both reflect severity of disease, or one may contribute to the development of the other. We found no difference in mortality or other supportive treatments (mechanical ventilation, vasoactive treatment) between patients with and without VTE, but our study is likely underpowered to detect such differences.

Strengths of our study include that all physicians in the screening programme were residents with very limited experience of DVT ultrasound that were given a brief ultrasound education. In our experience, most ICU physicians are not proficient in DVT-ultrasound. This study therefore probably reflects the pre-existing level of experience and screening implementation process at most centres during the COVID-19 pandemic, which increases generalizability.

Our study also has limitations. The small sample size decreases statistical power and the single centre setting reduces generalizability. Not all eligible patients were included, which may have led to selection bias, and undiagnosed fatal PE may have led to underestimation of the incidence of VTE [43]. Using DVT diagnosed during follow-up instead of formal ultrasound in cases of negative screening may have led to missed false negatives. One positive screening was not confirmed on formal ultrasound. This underscores the need for confirmation of pathological screening ultrasound and that negative screening should not defer formal examination when there is clinical suspicion of DVT. However, all DVT cases discovered in this study would likely have been missed and not received adequate treatment without screening, indicating possible benefit for patients. The present study may serve as a basis for future larger studies which may define estimates for sensitivity, specificity and predictive values.

\section{Conclusion}

ICU residents with limited experience in DVT ultrasound could detect DVT in critically ill COVID-19 patients following a brief education session. VTE was associated with more severe kidney dysfunction, more marked inflammatory response and features of hypercoagulation. Point-of-care ultrasound screening for DVT may be a resource-sparing alternative to expert CDUS screening in the setting of the COVID-19 pandemic.

\section{Abbreviations}

AKI: Acute kidney injury; BMI: Body mass index; CDUS: Complete duplex ultrasound; CRP: C-reactive peptide; CRRT: Continuous renal replacement therapy; CTPA: Computed tomography pulmonary angiography; 2-CUS: Tworegion compression ultrasound; DVT: Deep vein thrombosis; ECUS: Extended compression ultrasound; ICU: Intensive care Unit; IL-6: Interleukin 6; IU: International unit; IQR: Interquartile range; LMWH: Low molecular weight heparin; NT-pro-BNP: N-Terminal pro brain natriuretic peptide; PE: Pulmonary embolism; SD: Standard deviation; VTE: Venous thromboembolism

\section{Acknowledgements}

The authors thank Elin Söderman, Joanna Wessbergh, Erik Danielsson and Philip Karlsson for excellent technical and administrative assistance.

We also thank the collaborators of the Uppsala Intensive Care COVID-19 research group:

Tomas Luther, Sara Bülow Anderberg, Anna Gradin, Sten Rubertsson and Katja Hanslin.

\section{Authors' contributions}

Rosén J conceived the study. Galien S, Rosén J and Frithiof R contributed to the design of the study. Galien S, Hultström M, Lipcsey M, Stattin K, Frithiof R and Rosén J collected patient data. Galien S and Rosén J performed data analysis. The first draft of the manuscript was written by Galien S. All authors commented on previous versions of the manuscript. All authors read and approved the final manuscript for publication.

\section{Funding}

The study was funded by the SciLifeLab/KAW national COVID-19 research program project grant to MH (KAW 2020.0182), and the Swedish Research Council to RF (2014-02569 and 2014-07606). Open Access funding provided by Uppsala University.

\section{Availability of data and materials}

The datasets used and/or analyzed during the current study are available from the corresponding author on reasonable request (https://doi.org/10. 17044/scilifelab.14229410)

\section{Declarations}

\section{Ethics approval and consent to participate}

This study was approved by the National Ethical Review Agency (EPM; 202001623). Written informed consent was obtained from the patients, or next of kin if the patient was unable to give consent.

Consent for publication

Not applicable.

Competing interests

The authors declare that they have no competing interests. 


\section{Author details}

'Department of Surgical Sciences, Anaesthesiology and Intensive Care Medicine, Uppsala University, entrance 78, 1 floor, 75185 Uppsala, Sweden. ${ }^{2}$ Department of Medical Cell Biology, Integrative Physiology, Uppsala University, Uppsala, Sweden. ${ }^{3}$ Hedenstierna laboratory, CIRRUS, Department of Surgical Sciences, Anaesthesiology and Intensive Care Medicine, Uppsala University, Uppsala, Sweden.

\section{Received: 2 February 2021 Accepted: 15 March 2021} Published online: 02 June 2021

\section{References}

1. Tang N, Li D, Wang X, Sun Z. Abnormal coagulation parameters are associated with poor prognosis in patients with novel coronavirus pneumonia. J Thromb Haemost JTH. 2020;18(4):844-7. https://doi.org/1 $0.1111 /$ jth. 14768

2. Tang N, Bai H, Chen X, Gong J, Li D, Sun Z. Anticoagulant treatment is associated with decreased mortality in severe coronavirus disease 2019 patients with coagulopathy. J Thromb Haemost JTH. 2020;18(5):1094-9. https://doi.org/10.1111/jth.14817.

3. Klok FA, Kruip MJHA, van der Meer NJM, Arbous MS, Gommers D, Kant KM, Kaptein FHJ, van Paassen J, Stals MAM, Huisman MV, Endeman H. Confirmation of the high cumulative incidence of thrombotic complications in critically ill ICU patients with COVID-19: an updated analysis. Thromb Res. 2020;191:148-50. https://doi.org/10.1016/j.thromres.2020.04.041.

4. Cui S, Chen S, Li X, Liu S, Wang F. Prevalence of venous thromboembolism in patients with severe novel coronavirus pneumonia. J Thromb Haemost JTH. 2020;18(6):1421-4. https://doi.org/10.1111/jth.14830.

5. Middeldorp S, Coppens M, van Haaps TF, Foppen M, Vlaar AP, Müller MCA, et al. Incidence of venous thromboembolism in hospitalized patients with COVID-19. J Thromb Haemost JTH. 2020;18(8):1995-2002. https://doi.org/1 $0.1111 /$ jth.14888

6. Helms J, Tacquard C, Severac F, Leonard-Lorant I, Ohana M, Delabranche X, et al. High risk of thrombosis in patients with severe SARS-CoV-2 infection: a multicenter prospective cohort study. Intensive Care Med. 2020:46(6):1089_ 98. https://doi.org/10.1007/s00134-020-06062-x.

7. Lodigiani C, lapichino G, Carenzo L, Cecconi M, Ferrazzi P, Sebastian T, Kucher N, Studt JD, Sacco C, Bertuzzi A, Sandri MT, Barco S, Humanitas COVID-19 Task Force. Venous and arterial thromboembolic complications in COVID-19 patients admitted to an academic hospital in Milan. Italy Thromb Res. 2020;191:9-14. https://doi.org/10.1016/j.thromres.2020.04.024.

8. Williams MT, Phil NAM, Wallace MJ, Riedel BJCJ, Shaw ADS. Venous thromboembolism in the intensive care unit. Crit Care Clin Elsevier. 2003; 19(2):185-207. https://doi.org/10.1016/S0749-0704(02)00048-9.

9. Tavazzi G, Civardi L, Caneva L, Mongodi S, Mojoli F. Thrombotic events in SARS-CoV-2 patients: an urgent call for ultrasound screening. Intensive Care Med. 2020;46(6):1121-3. https://doi.org/10.1007/s00134-020-06040-3.

10. Laurence N, Cronan JJ, Lilly MP, Merli GJ, Srikar A, Hertzberg BS, et al. Ultrasound for Lower Extremity Deep Venous Thrombosis. Circulation. 2018; 137:1505-15.

11. Dua A, Thondapu V, Rosovsky R, Hunt D, Latz C, Waller HD, et al. Deep vein thrombosis protocol optimization to minimize healthcare worker exposure in coronavirus disease-2019. J Vasc Surg Venous Lymphat Disord. 2020;0 Available from: https://www.jvsvenous.org/article/S2213-333X(20)30438-8/a bstract. [cited 2020 Oct 22]

12. Burnside PR, Brown MD, Kline JA. Systematic review of emergency physician-performed ultrasonography for lower-extremity deep vein thrombosis. Acad Emerg Med Off J Soc Acad Emerg Med. 2008;15(6):493-8. https://doi.org/10.1111/j.1553-2712.2008.00101.x.

13. Pomero F, Dentali F, Borretta V, Bonzini M, Melchio R, Douketis JD, Fenoglio LM. Accuracy of emergency physician-performed ultrasonography in the diagnosis of deep-vein thrombosis: a systematic review and meta-analysis. Thromb Haemost. 2013;109(01):137-45. https://doi.org/10.1160/TH12-07-0473.

14. Kory PD, Pellecchia CM, Shiloh AL, Mayo PH, DiBello C, Koenig S. Accuracy of ultrasonography performed by critical care physicians for the diagnosis of DVT. Chest. 2011;139(3):538-42. https://doi.org/10.1378/chest.10-1479.

15. Kapoor S, Chand S, Dieiev V, Fazzari M, Tanner T, Lewandowski DC, et al. Thromboembolic events and role of point of care ultrasound in hospitalized Covid-19 patients needing intensive care unit admission. J Intensive Care Med. 2020;1-8. https://doi.org/10.1177/0885066620964392.
16. Adhikari S, Zeger W, Thom C, Fields JM. Isolated deep venous thrombosis: implications for 2-point compression ultrasonography of the lower extremity. Ann Emerg Med. 2015;66(3):262-6. https://doi.org/10.1016/j.a nnemergmed.2014.10.032

17. Demelo-Rodríguez P, Cervilla-Muñoz E, Ordieres-Ortega L, Parra-Virto A, Toledano-Macías M, Toledo-Samaniego N, García-García A, GarcíaFernández-Bravo I, Ji Z, de-Miguel-Diez J, Álvarez-Sala-Walther LA, del-ToroCervera J, Galeano-Valle F. Incidence of asymptomatic deep vein thrombosis in patients with COVID-19 pneumonia and elevated D-dimer levels. Thromb Res. 2020;192:23-6. https://doi.org/10.1016/j.thromres.2020.05.018.

18. Llitjos J-F, Leclerc M, Chochois C, Monsallier J-M, Ramakers M, Auvray M, Merouani K. High incidence of venous thromboembolic events in anticoagulated severe COVID-19 patients. J Thromb Haemost JTH. 2020; 18(7):1743-6. https://doi.org/10.1111/jth.14869.

19. Nahum J, Morichau-Beauchant T, Daviaud F, Echegut P, Fichet J, Maillet J-M, et al. Venous Thrombosis Among Critically III Patients With Coronavirus Disease 2019 (COVID-19). JAMA Netw Open. 2020;3 Available from: https:// www.ncbi.n/m.nih.gov/pmc/articles/PMC7260620/. [cited 2020 Oct 22].

20. Bin R, Feifei $Y$, Deng $Z$, Sheng $Z$, Lingfei $X$, Wu $M$, et al. Extremely high incidence of lower extremity deep venous thrombosis in 48 patients with severe COVID-19 in Wuhan. Circulation. 2020;142:181-3.

21. Santoliquido A, Porfidia A, Nesci A, De Matteis G, Marrone G, Porceddu E, et al. Incidence of deep vein thrombosis among non-ICU patients hospitalized for COVID-19 despite pharmacological thromboprophylaxis. J Thromb Haemost JTH. 2020;18(9):2358-63. https://doi.org/10.1111/jth.14992.

22. Voicu S, Bonnin P, Stépanian A, Chousterman BG, Le Gall A, Malissin I, et al. High prevalence of deep vein thrombosis in mechanically ventilated COVID19 patients. J Am Coll Cardiol. 2020;76(4):480-2. https://doi.org/10.1016/j.ja cc.2020.05.053.

23. lerardi AM, Coppola A, Fusco S, Stellato E, Aliberti S, Andrisani MC, et al. Early detection of deep vein thrombosis in patients with coronavirus disease 2019: who to screen and who not to with Doppler ultrasound? J Ultrasound. 2020;1-8.

24. Grandmaison G, Andrey A, Périard D, Engelberger RP, Carrel G, Doll S, et al. Systematic screening for venous thromboembolic events in COVID-19 pneumonia. TH Open Companion J Thromb Haemost. 2020:4:e113-5.

25. Giorgi-Pierfranceschi M, Paoletti O, Pan A, De Gennaro F, Nardecchia AL, Morandini $\mathrm{R}$, et al. Prevalence of asymptomatic deep vein thrombosis in patients hospitalized with SARS-CoV-2 pneumonia: a cross-sectional study. Intern Emerg Med. 2020;15:1425-33.

26. Longchamp A, Longchamp J, Manzocchi-Besson S, Whiting L, Haller C, Jeanneret S, et al. Venous Thromboembolism in Critically III Patients with Covid-19: Results of a Screening Study for Deep Vein Thrombosis. Res Pract Thromb Haemost. 2020; Available from: https://www.ncbi.nlm.nih.gov/ pmc/articles/PMC7272794/. [cited 2020 Oct 22].

27. Franco-Moreno A, Herrera-Morueco M, Mestre-Gómez B, Muñoz-Rivas N Abad-Motos A, Salazar-Chiriboga D, et al. Incidence of deep venous thrombosis in patients with COVID-19 and pulmonary embolism: compression ultrasound COVID study. J Ultrasound Med Off J Am Inst Ultrasound Med. 2020;1-8.

28. Luther T, Bülow-Anderberg S, Larsson A, Rubertsson S, Lipcsey M, Frithiof R, et al. COVID-19 patients in intensive care develop predominantly oliguric acute kidney injury. Acta Anaesthesiol Scand. [cited 2021 Jan 17];n/a. Available from: https://onlinelibrary.wiley.com/doi/abs/10.1111/aas.13746.

29. $V m R, G d R, B t T, N d F, E C, E F$, et al. Acute respiratory distress syndrome: the Berlin Definition [Internet]. JAMA. 2012; [cited 2020 Dec 2]. Available from: http://pubmed.ncbi.nlm.nih.gov/22797452/.

30. Hardy M, Douxfils J, Bareille M, Lessire S, Gouin-Thibault I, Fontana P, Lecompte T, Mullier F. Studies on hemostasis in COVID-19 deserve careful reporting of the laboratory methods, their significance, and their limitations. J Thromb Haemost JTH. 2020;18(11):3121-4. https://doi.org/1 $0.1111 /$ jth.15061.

31. Hardy M, Lecompte T, Douxfils J, Lessire S, Dogné JM, Chatelain B, Testa S, Gouin-Thibault I, Gruel Y, Medcalf RL, ten Cate H, Lippi G, Mullier F. Management of the thrombotic risk associated with COVID-19: guidance for the hemostasis laboratory. Thromb J. 2020;18(1):17. https://doi.org/10.1186/ s12959-020-00230-1.

32. Moreno RP, Metnitz PGH, Almeida $E$, Jordan B, Bauer $P$, Campos RA lapichino G, Edbrooke D, Capuzzo M, le Gall JR, on behalf of the SAPS 3 Investigators. SAPS 3--from evaluation of the patient to evaluation of the intensive care unit. Part 2: development of a prognostic model for hospital 
mortality at ICU admission. Intensive Care Med. 2005;31(10):1345-55. https:// doi.org/10.1007/s00134-005-2763-5

33. Roberts L, Rozen T, Murphy D, Lawler A, Fitzgerald M, Gibbs H, Brooks K, Ihle JF, Leong T, Orosz J, Paul E, Nanjayya VB. A preliminary study of intensivist-performed DVT ultrasound screening in trauma ICU patients (APSIT study). Ann Intensive Care. 2020;10(1):122. https://doi.org/10.1186/s13 613-020-00739-8.

34. Le Jeune S, Suhl J, Benainous R, Minvielle F, Purser C, Foudi F, et al. High prevalence of early asymptomatic venous thromboembolism in anticoagulated COVID-19 patients hospitalized in general wards. J Thromb Thrombolysis. 2020;1-5.

35. van Dam LF, Kroft LM, van der Wal LI, Cannegieter SC, Eikenboom J, de Jonge $\mathrm{E}$, et al. Clinical and computed tomography characteristics of COVID19 associated acute pulmonary embolism: a different phenotype of thrombotic disease? Thromb Res. 2020;193:86-9.

36. Dujardin RWG, Hilderink BN, Haksteen WE, Middeldorp S, Vlaar APJ, Thachil J, Müller MCA, Juffermans NP. Biomarkers for the prediction of venous thromboembolism in critically ill COVID-19 patients. Thromb Res. 2020;196: 308-12. https://doi.org/10.1016/j.thromres.2020.09.017.

37. Shi C, Wang C, Wang H, Yang C, Cai F, Zeng F, Cheng F, Liu Y, Zhou T, Deng B, Vlodavsky I, Li JP, Zhang Y. The potential of low molecular weight heparin to mitigate cytokine storm in severe COVID-19 patients: a retrospective cohort study. Clin Transl Sci. 2020;13(6):1087-95. https://doi. org/10.1111/cts.12880.

38. Nils K, Goldhaber Samuel Z. Cardiac Biomarkers for Risk Stratification of Patients With Acute Pulmonary Embolism. Circulation. 2003;108:2191-4.

39. Zheng Y-Y, Ma Y-T, Zhang J-Y, Xie X. COVID-19 and the cardiovascular system. Nat Rev Cardiol. 2020;17(5):259-60. https://doi.org/10.1038/s41569020-0360-5.

40. Nadim MK, Forni LG, Mehta RL, Connor MJ, Liu KD, Ostermann M, et al. COVID19-associated acute kidney injury: consensus report of the 25th acute disease quality initiative (ADQI) workgroup. Nat Rev Nephrol. 2020;16:747-64.

41. Xu J, Xie J, Du B, Tong Z, Qiu H, Bagshaw SM. Clinical characteristics and outcomes of patients with severe COVID-19 induced acute kidney injury. J Intensive Care Med. 2021;36:319-26.

42. Cheng Y, Luo R, Wang K, Zhang M, Wang Z, Dong L, Li J, Yao Y, Ge S, Xu G. Kidney disease is associated with in-hospital death of patients with COVID19. Kidney Int. 2020;97(5):829-38. https://doi.org/10.1016/j.kint.2020.03.005.

43. Wichmann D, Sperhake J-P, Lütgehetmann M, Steurer S, Edler C, Heinemann $A$, et al. Autopsy findings and venous thromboembolism in patients with COVID-19: a prospective cohort study. Ann Intern Med. 2020; 173:268-77.

\section{Publisher's Note}

Springer Nature remains neutral with regard to jurisdictional claims in published maps and institutional affiliations.

Ready to submit your research? Choose BMC and benefit from:

- fast, convenient online submission

- thorough peer review by experienced researchers in your field

- rapid publication on acceptance

- support for research data, including large and complex data types

- gold Open Access which fosters wider collaboration and increased citations

- maximum visibility for your research: over $100 \mathrm{M}$ website views per year

At BMC, research is always in progress.

Learn more biomedcentral.com/submissions 